\title{
Alcohol-related cirrhosis
}

Charles Lieber

\section{Source}

Charles Lieber. (1965). Effects of prolonged ethanol intake: Production of fatty liver despite adequate diets. J Clin Invest, vol. 44 . http://content-assets.jci.org/manuscripts/105000/105200/JC165105200.pdf.

Alcohol ingestion produces fatty livers, despite maintenance of adequate diets.. Excessive and chronic alcohol intake can lead to cirrhosis 